\title{
KASP Markers Specific for the Fertility Restorer Locus $R f 1$ and Application for Genetic Purity Testing in Sunflowers (Helianthus annuus L.)
}

\author{
Aleksandra Radanović ${ }^{1}$, Yves Sprycha ${ }^{2}$, Milan Jocković ${ }^{1}\left(\mathbb{D}\right.$, Monja Sundt $^{2}$, Dragana Miladinović $^{1}{ }^{(D)}$ \\ Constantin Jansen ${ }^{3,+}$ and Renate Horn ${ }^{2, *}$ (D) \\ 1 Institute of Field and Vegetable Crops, Maksima Gorkog 30, 21000 Novi Sad, Serbia; \\ aleksandra.dimitrijevic@ifvens.ns.ac.rs (A.R.); milan.jockovic@ifvens.ns.ac.rs (M.J.); \\ dragana.miladinovic@ifvens.ns.ac.rs (D.M.) \\ 2 Department of Plant Genetics, Institute of Biological Sciences, University of Rostock, Albert-Einstein-Str. 3, \\ D-18059 Rostock, Germany; yves.sprycha@outlook.de (Y.S.); monja.sundt@uni-rostock.de (M.S.) \\ 3 Strube Research GmbH \& Co. KG, Hauptstr. 1, D-38387 Söllingen, Germany; constantin.jansen@graminor.no \\ * Correspondence: renate.horn@uni-rostock.de \\ † Present address: Graminor AS, Hommelstadvegen 60, 2322 Ridabu, Norway.
}

\section{check for}

updates

Citation: Radanović, A.; Sprycha, Y.; Jocković, M.; Sundt, M.; Miladinović, D.; Jansen, C.; Horn, R. KASP Markers Specific for the Fertility Restorer Locus Rf1 and Application for Genetic Purity Testing in Sunflowers (Helianthus annuus L.). Genes 2022, 13, 465. https://doi.org/ $10.3390 /$ genes 13030465

Academic Editor: Gabriella De Lorenzis

Received: 9 February 2022

Accepted: 2 March 2022

Published: 5 March 2022

Publisher's Note: MDPI stays neutral with regard to jurisdictional claims in published maps and institutional affiliations.

Copyright: (C) 2022 by the authors. Licensee MDPI, Basel, Switzerland. This article is an open access article distributed under the terms and conditions of the Creative Commons Attribution (CC BY) license (https:// creativecommons.org/licenses/by/ $4.0 /)$.

\begin{abstract}
Single nucleotide polymorphisms (SNPs) were significantly associated with fertility restoration of cytoplasmic male sterility (CMS) PET1 by the restorer gene Rf1. For these SNPs, four Kompetitive allele-specific PCR (KASP) markers were successfully designed. The KASP markers cover the fertility restorer locus $R f 1$, spanning about $3 \mathrm{Mb}$, and clearly differentiate restorer and maintainer lines. For genetic purity testing in sunflower hybrid production, the efficiency for detecting contaminations in samples was simulated using mixtures of hypocotyls or leaves. Contaminations of restorer lines with $1 \%, 3 \%, 5 \%, 10 \%$, and $50 \%$ of maintainer lines were screened with all four KASP markers. Contaminations of $10 \%$ could be clearly detected in pools of 100 plants. Contaminations below this level require detection on a single plant level. For single plant detections, ethyl methanesulfonate-treated sunflower F1 hybrids, which had been phenotypically evaluated for male sterility (potential mutation in the Rf1 gene) were screened. Nine identified either partially male-sterile or male-sterile plants were analyzed with all four KASP markers and only one proved to be a hybrid with a mutation, seven were male-sterile contaminants in the F1 seeds used (1.6\%) and one a recombinant plant. The four KASP markers should be valuable tools for marker-assisted selection (MAS) in sunflower breeding regarding the restorer locus $R f 1$.
\end{abstract}

Keywords: candidate gene; EMS mutagenesis; genetic purity; hybrid breeding; KASP marker; markerassisted selection; CMS PET1 cytoplasm; restorer gene Rf1; single nucleotide polymorphism; sunflower

\section{Introduction}

Sunflower breeding is based on hybrid production, which exploits heterosis, the phenotypic superiority of a hybrid over its parents. Hybrids are obtained by crossing male sterile (A) lines with restorer (R) lines. In sunflowers, the most commonly used cytoplasmic male sterility source is the CMS-PET1 cytoplasm [1]. The maternally transmitted trait is manifested in an inability to produce pollen due to rearrangements of the mitochondrial genome [2,3]. For the maintenance of A lines, fertile analogs, called maintainer or B lines, which carry a normal, fertile cytoplasm, are necessary.

Restoration of male fertility in the F1 hybrids requires dominantly inherited nuclear restorer-of-fertility $(R f)$ genes. Despite the availability of several $R f$ genes such as, e.g., $R f 3$ or $R f 5, R f 1$ has been the most widely exploited restorer gene in sunflower hybrid breeding for over four decades $[4,5]$. The fertility restorer gene $R f 1$ was introduced into sunflower breeding material from the T66006-2-1-B line [6]. The genetic nature of inheritance of $R f 1$ makes this trait very eligible for detection by use of molecular markers. In the past, Rf1 was 
positioned on linkage group (LG) 13 of the sunflower genetic reference map [7]. Different types of markers, such as restriction fragment length polymorphism (RFLP), randomamplified polymorphism DNA (RAPD), amplified fragment length polymorphism (AFLP), sequence characterized amplified region (SCAR), target region amplification polymorphism (TRAP), simple-sequence repeats (SSR), and cleaved amplified polymorphic sequences (CAPS) have been used for mapping the gene [7-10]. Advancements in technology and the availability of the sunflower reference genome [11] have enabled a more detailed analysis of the locus comprising the Rf1 gene. However, the Rf1 gene itself has not been identified mainly due to the complexity and size of the sunflower genome, represented by the maintainer line HanXRQ.

Recently, candidate genes for Rf1 have been identified using SNP-based association studies. Goryunov et al. [12] applied a genome-wide association study and found 21 candidate genes for Rf1 in a defined segment spanning 7.72 Mb on LG 13. Twenty of these genes belong to the pentatricopeptide repeat (PPR) gene family and one additional gene was annotated as a probable aldehyde dehydrogenase gene [13]. Talukder et al. [5] associated 24 SNP markers spanning $2.47 \mathrm{cM}$ on LG 13 with fertility restoration by genome-wide association studies (GWAS) using a mixed model analysis in a panel of 333 sunflower lines. Further studies demonstrated that 130 of the 548 examined lines had retained all 24 SNPs associated with Rf1 indicating an inheritance of all SNPs as one haplotype throughout decades of sunflower breeding [5]. However, these 24 SNPs were also present in three maintainer lines released by the Agricultural Research Service (ARS) of the United States Department of Agriculture (USDA). Finally, Horn et al. [14] were able to narrow down the number of candidate genes for fertility restoration to three candidate genes belonging to the PPR gene family (HanXRQChr13g0419621, HanXRQChr13g0418841, and HanXRQChr13g0418861). These three genes were identified by 10 SNPs significantly associated with fertility restoration in an association study using 32 restorer and 27 maintainer lines. For this purpose, amplicon-targeted sequencing of nine potential candidate genes was used to obtain the gene sequences for the SNP analyses. Three SNP-based markers, one co-dominant PAMSA (polymerase chain reaction (PCR) amplification of multiple specific alleles), and two dominant markers were developed, which clearly differentiate restorer from maintainer lines [14]. All three gel-based markers were verified in an association panel consisting of 557 sunflower accessions.

Polivanova et al. [15] found significant variability in the Rf1 locus (position 169,655,088 to $178,217,103$, HanXRQr1.0 annotation) by using PCR gene-specific primer pairs for the previously investigated 25 potential candidate genes for $R f 1$ [12,14].

Real-time PCR markers for high-throughput detection of the Rf1 gene would greatly facilitate and add to the cost-effectiveness in hybrid production, especially in sunflowers, the second most important crop based on hybrid breeding [16]. Assessing the genetic purity of the hybrid components represents an essential quality control function in hybrid production. The genetic purity of the seeds can be compromised by out-crossing with foreign pollen, but also by seed contaminations $[17,18]$. Several approaches are applied to analyze genetic purity: (1) grow out test (GOT), (2) use of biochemical, and (3) molecular markers. While the first approach is based on detecting morphological differences, the second and the third are oriented towards detecting protein/isoenzyme and DNA profiles, respectively. From the three techniques, molecular markers are the most precise, especially if co-dominantly inherited. First, RAPD markers were used directly [19] or converted into SCARs for analyzing hybrid purity [20]. To this day, the most commonly used type of markers for genetic purity assessment are SSRs, which are co-dominant and highly polymorphic. In addition, other sets of markers have been used to distinguish inbred lines $[17,21,22]$. However, none of the mentioned marker techniques are as prone to automatization, high-throughput, and cost-effectiveness as the new real-time marker platforms developed for the detection of SNPs, such as TaqMan, KASP, high-resolution melting (HRM), and rhAmp. KASP is a single-step genotyping technology based on an end-point real-time PCR amplification coupled with fluorescence detection [23]. KASP as- 
says have already been successfully used for the detection of $R f$ genes in other crop species such as sorghum [24] and pepper [25]. In rice, KASPs were exploited for the detection of two thermo-sensitive genic male sterility genes ( $p / t m s 12-1$ and $t m s 9-1)$ in analyses for seed purity [26]. In wheat, KASP assays showed 45 times higher superiority in speed over classical gel-based markers [27].

In this study, four KASP markers were developed for the detection of SNPs significantly associated with the three potential candidate genes for the $R f 1$ gene in sunflowers [14]. KASP assays were tested in a selected panel of restorer lines, maintainer lines, and hybrids in order to access their potential use in marker-assisted selection (MAS). Furthermore, the potential sensitivity of the developed markers in genetic purity testing in hybrid breeding was investigated by analyzing mixtures representing different levels of contaminations. In addition, single plant detections of ethyl methanesulfonate-treated (EMS) sunflower F1hybrid plants, which had been phenotypically screened for male sterility, were performed.

\section{Materials and Methods}

\subsection{Sunflower Plant Material}

Nine maintainer lines and nine restorer lines as well as 18 hybrids of these lines were used to validate the KASP markers. The hybrids were obtained by either crossing the maintainer lines with a commercial restorer tester or by pollinating a commercial CMStester with the restorer lines of the panel (Table S1). Male fertility of the F1 hybrids was confirmed in the field at Bandow/Schwaan (Germany) in 2019. In addition, three other maintainer and five other restorer lines of the PET1 cytoplasm were included in the study.

For simulation of contaminations in inbred lines, seedlings were grown in a growth chamber for three weeks and pools of 100 hypocotyl pieces $(1 \mathrm{~cm})$ were generated representing $1 \%, 3 \%, 5 \%, 10 \%$, and $50 \%$ contamination (Table S2). For simulation of contaminations, different amounts of two maintainer lines (UGA-SAM1-109 or UGA-SAM1-082) were added to two restorer lines (UGA_SAM1-136 or UGA-SAM1-191). In addition, leaf discs $(\varnothing 1 \mathrm{~cm})$ were cut from 3-weeks-old seedlings (Table S3). Contaminations of 1\%, 3\%, $5 \%, 10 \%$, and $50 \%$ were investigated in comparison to both pure lines and four hybrids (LC $\times$ UGA-SAM1-136, LC × UGA-SAM1-109, UGA-SAM1-109 × R, UGA-SAM1-082 × R).

\subsection{EMS-Treatment of Sunflower Seeds}

A total of 1040 F1-hybrid (cmsHA342 × RHA325) seeds representing combined seed samples were treated with $0.8 \%$ or $1.2 \%$ ethyl methanesulfonate. For the mutagenesis treatment, seeds were pre-germinated for $24 \mathrm{~h}$ in $0.1 \% \mathrm{KCl}$ by slightly shaking them. After this period, the seeds were incubated with two different EMS concentrations $(0.8 \%$ or $1.2 \%$ ) for $18 \mathrm{~h}$. Finally, the seeds were washed three times with sodium thiosulfate to inactivate the toxic EMS. Seeds were immediately planted on the field and watered to secure germination. Germination rates were $41 \%(213 / 520)$ for the $0.8 \%$ EMS treatment and $41.9 \%$ (218/520) for 1.2\% EMS. Plants were scored for fertility in the field in 2019 at Bandow/Schwaan (Germany). Leaves were taken and frozen at $-20{ }^{\circ} \mathrm{C}$ for DNA analysis.

\subsection{DNA Extraction}

DNA was extracted from sunflower leaves harvested from the restorer and maintainer lines as well as the F1 hybrids in the field and stored at $-20{ }^{\circ} \mathrm{C}$. For the genetic purity testing, hypocotyl segments of sunflower seedlings $(1 \mathrm{~cm})$ were used that had been pooled according to the contamination protocol before being frozen in liquid nitrogen and stored at $-20^{\circ} \mathrm{C}$. Prior to DNA extraction, the pooled samples were homogenized using a pestle and mortar. The DNA was isolated by the CTAB protocol of Doyle and Doyle [28] starting with 200-400 mg leaf material or hypocotyls. The final DNA pellet was dissolved in TE buffer (1 mM EDTA, $10 \mathrm{mM}$ Tris $\mathrm{HCl} \mathrm{pH}$ 8.0) and diluted with sterile $\mathrm{ddH}_{2} \mathrm{O}$ to $15 \mathrm{ng} / \mu \mathrm{L}$ for KASP assays. 


\subsection{SNP Analyses Using Amplicon Targeted Sequences}

Ten maintainer lines and 10 restorer lines, used for validation of the KASP assays, belonged to the 59 sunflower accessions that were part of the amplicon targeted sequencing of nine potential candidate genes for Rf1 by LGC Genomics, Berlin, Germany [14]. Applying the Ovation Custom Target Enrichment System (NuGen Technologies, Tecan Group Ltd., Männedorf, Switzerland) library enrichment was performed, followed by sequencing on the MiSeq V3 subunit $(2 \times 300$ bp) with $120 \times$ coverage. Variant calls were executed by LGC Genomics and supplied in VCF files.

\subsection{KASP Primer Design}

KASP markers were designed for four SNPs significantly associated with fertility restoration of CMS PET1 by the restorer gene Rf1 [14]. Positions of the SNPs and the three genes are given in the new sunflower genome sequence assembly in comparison to the old assembly in Table S4. The sequences around the SNPs are shown in Table S5. The PrimerQuest tool with the default setting of qPCR 2 Primers Intercalating Dyes (Primers only) (https:/ / www.idtdna.com/SciTools, last accessed on 3 March 2022) was used to design KASP primers (Table 1).

Table 1. KASP primers designed for the SNPs PPR621.5, PPRR621.11, PPR841.38, and PPR861.19.

\begin{tabular}{cc}
\hline Primer Name & Primer Sequences $\mathbf{( 5}^{\prime} \mathbf{- 3}^{\prime} \mathbf{~}^{\mathbf{1}}$ \\
\hline PPR621.5(G/C) & GAAGGTGACCAAGTTCATGCTACCAGTAATCTCCACATGAACATTG \\
621.5 F1_FAM & GAAGGTCGGAGTCAACGGATTACCAGTAATCTCCACATGAACATTC \\
621.5 F2_HEX & GCGATAAAGAAGCGGGAGATTA \\
621.5 R1 & \\
PPR621.11 (C/A) & GAAGGTGACCAAGTTCATGCTGCGGACGCTTGTATGTTC \\
621.11 F3_FAM & GAAGGTCGGAGTCAACGGATTGCGGACGCTTGTATGTTA \\
621.11 F4_HEX & TACGGGTGGACCCACAT \\
621.11 R3 & \\
PPR841.38(G/A) & GAAGGTGACCAAGTTCATGCTGCAAAGCACTTGTTTCGTAG \\
841.38 F3_FAM & GAAGGTCGGAGTCAACGGATTGCAAAGCACTTGTTTCGTAA \\
841.38 F4_HEX & ATCCCTGGAGAAGAACATTGT \\
841.38 R3 & \\
PPR861.19(G/C) & \\
861.19 F3_FAM & GAAGGTGACCAAGTTCATGCTAAAAGAAATGGAGGAGGATG \\
861.19 F4_HEX & GAAGGTCGGAGTCAACGGATTAAAAGAAATGGAGGAGGATC \\
861.19 R3 & CTTCATGCACCTTACCTTCC \\
\hline
\end{tabular}

${ }^{1}$ unique tail corresponding to the individual FRET cassettes is shown in italics.

For the development of the KASP markers, the length of the PCR products was restricted to $<150 \mathrm{bp}$ and an annealing temperature close to $62{ }^{\circ} \mathrm{C}$ was chosen. Each primer combination consists of two allele-specific primers with unique tails at the $5^{\prime}$ end corresponding to the universal FRET (fluorescence resonant energy transfer) cassette for each fluorescent dye (FAM: 5'-GAAGGTGACCAAGTTCATGCT-3' and HEX: $5^{\prime}$-GAAGGTCGGAGTCAACGGATT-3') and one common primer (Table 1). Primers were ordered from Biolegio (Nijmegen, Netherlands) and dissolved in TE buffer (1 mM EDTA, $10 \mathrm{mM}$ Tris $\mathrm{HCl} \mathrm{pH} \mathrm{8.0).} \mathrm{The} \mathrm{primer} \mathrm{mix} \mathrm{for} \mathrm{a} \mathrm{single} \mathrm{reaction} \mathrm{contained} 0.01 \mu \mathrm{L}$ of each allele-specific primer $(100 \mathrm{pmol} / \mu \mathrm{L})$ and $0.3 \mu \mathrm{L}$ of the common primer $(100 \mathrm{pmol} / \mu \mathrm{L})$ added up to $0.1 \mu \mathrm{L}$ with $0.05 \mu \mathrm{L} \mathrm{ddH}_{2} \mathrm{O}$.

\subsection{KASP-Marker Assay}

For the KASP assay, a slightly modified protocol according to Patterson et al. [29] was used. The assays were run on a LightCycler 96 (Roche Diagnostic, Mannheim, Germany). Each reaction $(8 \mu \mathrm{L})$ contained $4 \mu \mathrm{L}$ DNA $(15 \mathrm{ng} / \mu \mathrm{L})$ or $4 \mu \mathrm{L} \mathrm{ddH}_{2} \mathrm{O}$ as a negative control, $0.1 \mu \mathrm{L}$ primer mix and 3.9 $\mu \mathrm{L}$ KASP master mix (LGC Genomics, Berlin, Germany) containing the universal FRET cassettes for FAM and HEX labeled oligonucleotides, low ROX 
passive reference dye, Taq polymerase, dNTPs, buffer with optimized $\mathrm{MgCl}_{2}$ concentration. The PCR program began with a hot start activation at $94{ }^{\circ} \mathrm{C}$ for $900 \mathrm{~s}$, followed by 10 cycles of touchdown PCR (denaturation: $94^{\circ} \mathrm{C}$ for $20 \mathrm{~s}$, polymerization: starting at $61^{\circ} \mathrm{C}$ with a sequential reduction in the temperature by $0.6{ }^{\circ} \mathrm{C}$ to $55^{\circ} \mathrm{C}$ ), followed by 26 cycles (denaturation: $94{ }^{\circ} \mathrm{C}$ for $20 \mathrm{~s}$, polymerization: $55^{\circ} \mathrm{C}$ for $60 \mathrm{~s}$ ) and 2 cycles $37^{\circ} \mathrm{C}$ for $60 \mathrm{~s}$, $37^{\circ} \mathrm{C}$ for $10 \mathrm{~s}$. Results of the PCR were determined as end-point readings after lowering the temperature to $37^{\circ} \mathrm{C}$.

\subsection{Data Analysis}

For the data analysis the measured fluorescence values for FAM and HEX were transformed into percentages of fluorescence $(\% \mathrm{~F})$ by adjusting them to the corresponding minimum and maximum fluorescence values for each fluorescence dye on each measured plate, respectively. This has to be performed separately for each fluorescence dye, either Hex or Fam. The following modified formula according to Oliveira et al. [30] was used:

$$
\% \mathrm{~F}=(\mathrm{X}-\min . \mathrm{F} / \max . \mathrm{F}-\min . \mathrm{F}) \times 100
$$

where $\mathrm{X}$ represents the measured fluorescence of the individual dye, either Hex or Fam, min. $\mathrm{F}$ is the lowest fluorescence value (minimum) measured on the 96-well plate for the respective dye and max. $\mathrm{F}$ is the highest fluorescence value of the respective dye (maximum) for this plate measurement. A no amplification zone was defined below $25 \%$ for the fluorescence values, as the data points of the negative controls carrying no template or assays not amplifying were located in this area. Two replications per sample were sufficient for the differentiation between maintainer lines, restorer lines, and hybrids, but four replications per sample were applied for the contamination testing and the screening of the EMS mutants. The dashed lines represent the borders for scoring into the different classes (restorer, hybrid, maintainer). In the ideal case as for KASP 621.5, the two dashed lines separate the 90 degrees into three 30-degree segments.

\section{Results}

\subsection{Development of KASP Markers Based on SNPs Associated with Fertility Restoration}

Starting with 10 SNPs, which had been significantly associated with fertility restoration of the PET1 cytoplasm [14], four SNPs (PPR621.5, G > C; PPR621.11, C > A; PPR841.38, G > A; and PPR861.19, G > C) were selected for the development of KASP markers because these were reported to be homozygous in the restorer lines. Locations of all 10 SNPs in the new sunflower genome assembly HanXRQv2 are given in Figure 1. For all selected SNPs, KASP markers could be developed.

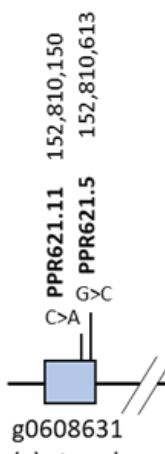

(+) strand
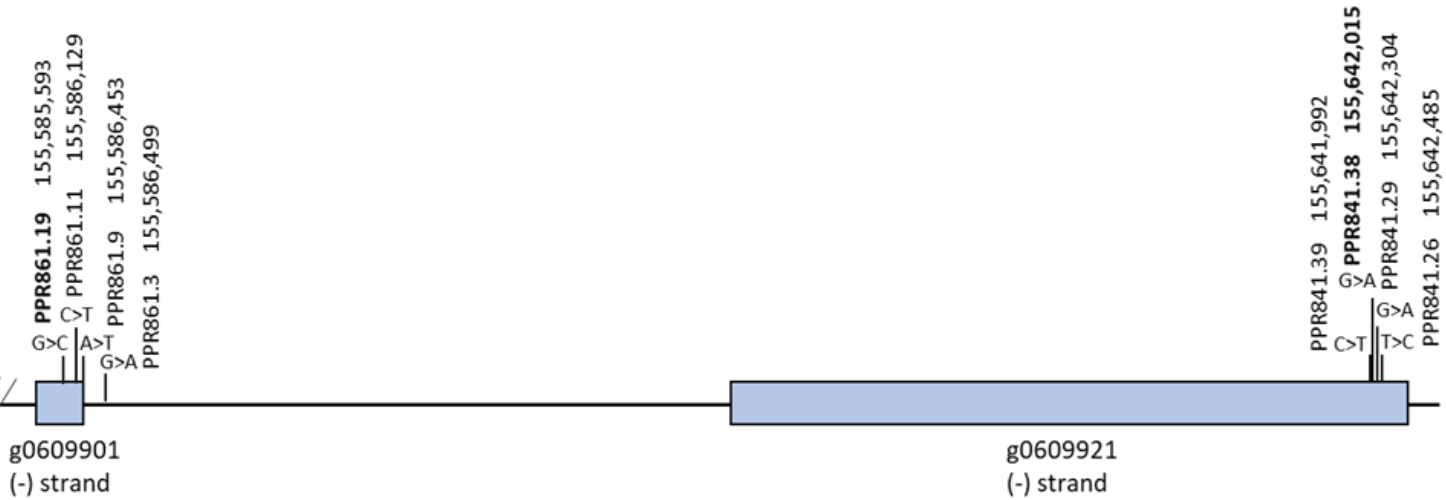

$\sim 3 \mathrm{Mb}$

Figure 1. Locations of SNPs significantly associated with the fertility restorer locus $R f 1$ in the new sunflower genome assembly HanXRQr2. SNPs successfully used for KASP marker design are shown in bold. 
The four KASP markers $(621.5,621.11,841.38$ and 861.19$)$ represent the three potential gene candidates HanXRQr2_Chr13g0608631, HanXRQr2_Chr13g0609921, and HanXRQr2 Chr13g0609901 at the restorer locus $R f 1$, spanning a genome region of about $3 \mathrm{Mb}$ in the new whole-genome assembly HanXRQr2. The KASP markers were first validated with regard to their ability to differentiate between nine restorer lines, nine maintainer lines, and 18 F1 hybrids. In addition, three other maintainer and five additional restorer lines were included (Table S1).

The potential restorer gene HanXRQr2_Chr13g0608631 (PPR621) is represented by two KASP markers for the SNPs PPR621.5 and PPR621.11. The first one, KASP marker 621.5 , gave the best separation between restorer lines, maintainer lines, and F1 hybrids (Figure 2a). Interestingly, one of the tested restorer lines, IH-51, carries the PET1 cytoplasm and is not only a restorer line for PET1 but also a restorer line for the PET2 cytoplasm [31], behaved differently than expected. IH-51 was clearly grouped with the maintainer lines indicating the absence of Rf1 in IH-51 despite its restoration ability towards PET1.

In the differentiation of restorer lines, maintainer lines, and hybrids, KASP marker 621.11 gave a slightly different picture compared to 621.5 as it splits the restorer lines into two groups (Figure 2b). Five of the restorer lines (UGA-SAM1-010, UGA-SAM1-024, UGA-SAM1-136, UGA-SAM1-161, and UGA-SAM1-191) formed a separate group closer to the F1 hybrids, but their hybrids with a commercial CMS tester tended also to be more located towards the maintainers still allowing a clear differentiation between restorer lines, maintainer lines, and F1 hybrids.

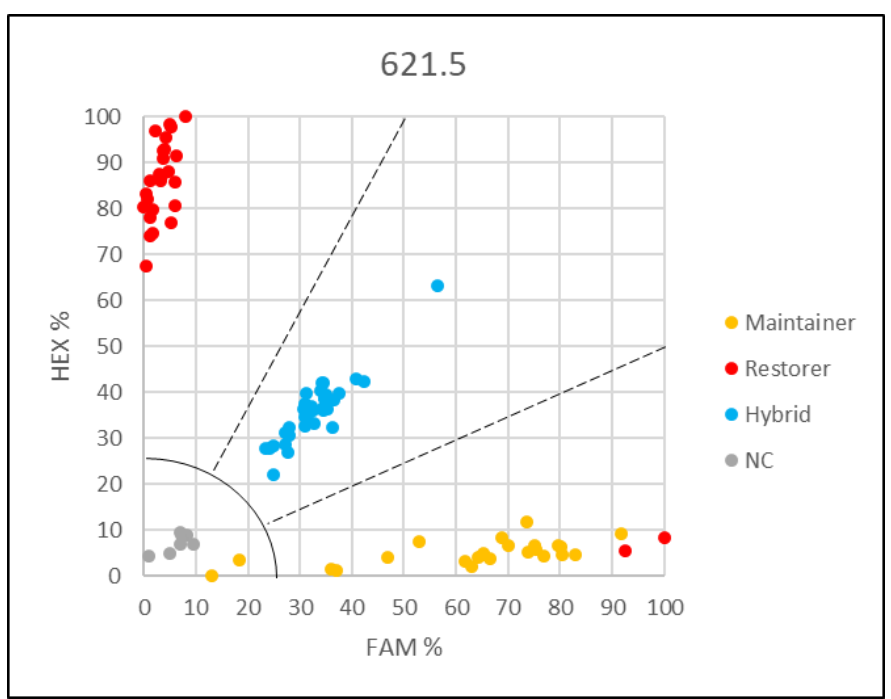

(a)

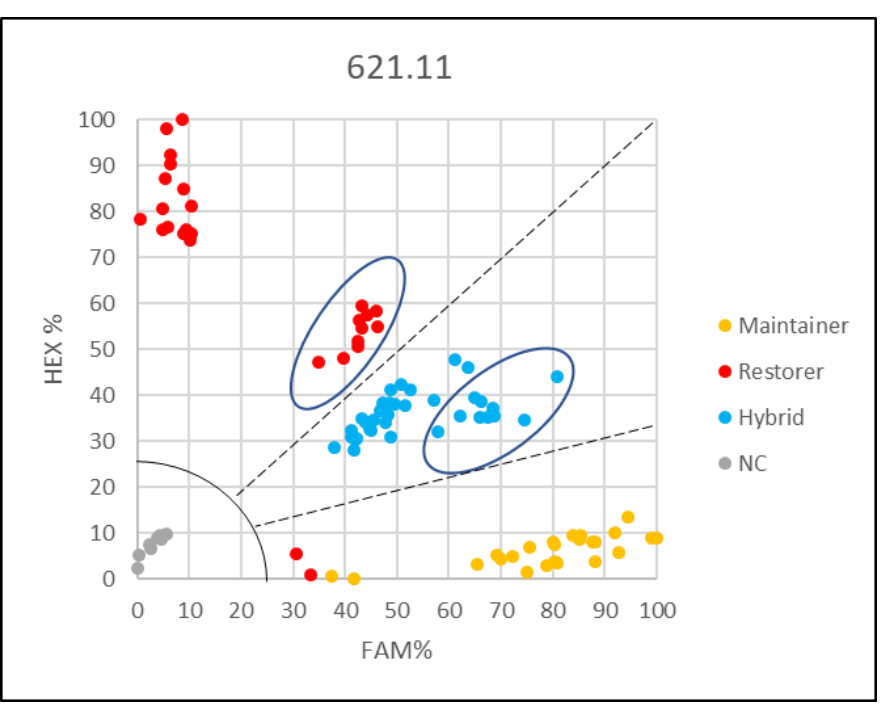

(b)

Figure 2. Grouping obtained by KASP markers (a) 621.5 and (b) 621.11. The latter splits the restorer lines into two groups. However, the outgroup of restorer lines (marked by an oval) can still be separated from their crosses to the CMS tester (also marked by an oval). NC negative control.

The two KASP markers for detecting the SNPs PPR841.38 and PPR861.19 located in the two other potential restorer candidate genes (HanXRQr2_Chr13g0609921 and HanXRQr2 Chr13g0609901, respectively) also gave a clear differentiation, but to a lesser degree (Figure 3). Using these two KASP markers in addition to 621.5 and 621.11 allows coverage of the whole restorer locus $R f 1$ of about $3 \mathrm{Mb}$ on LG 13 for analyses of recombination events. 


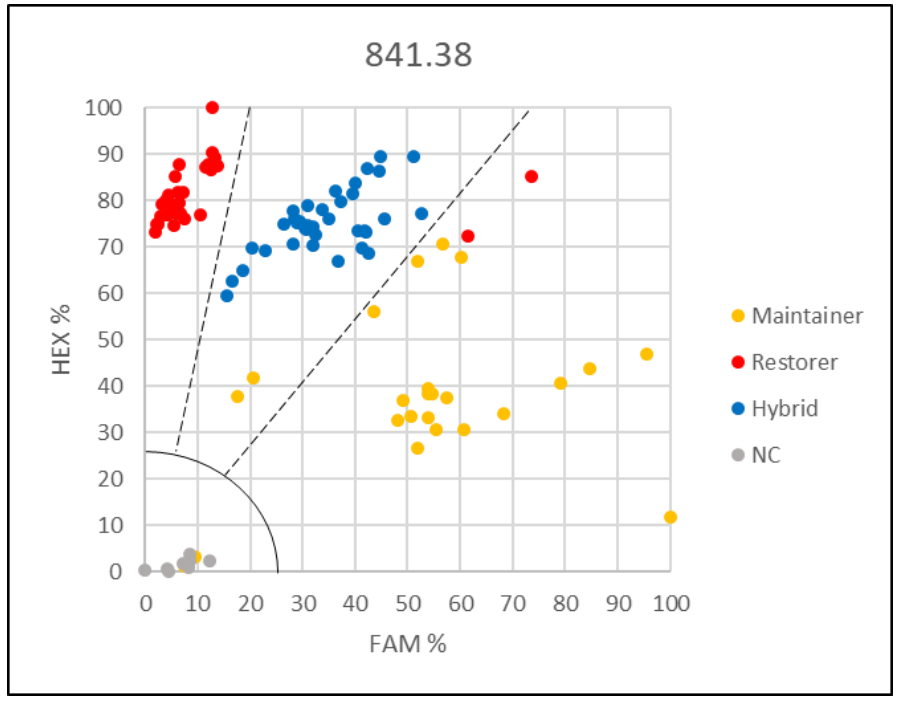

(a)

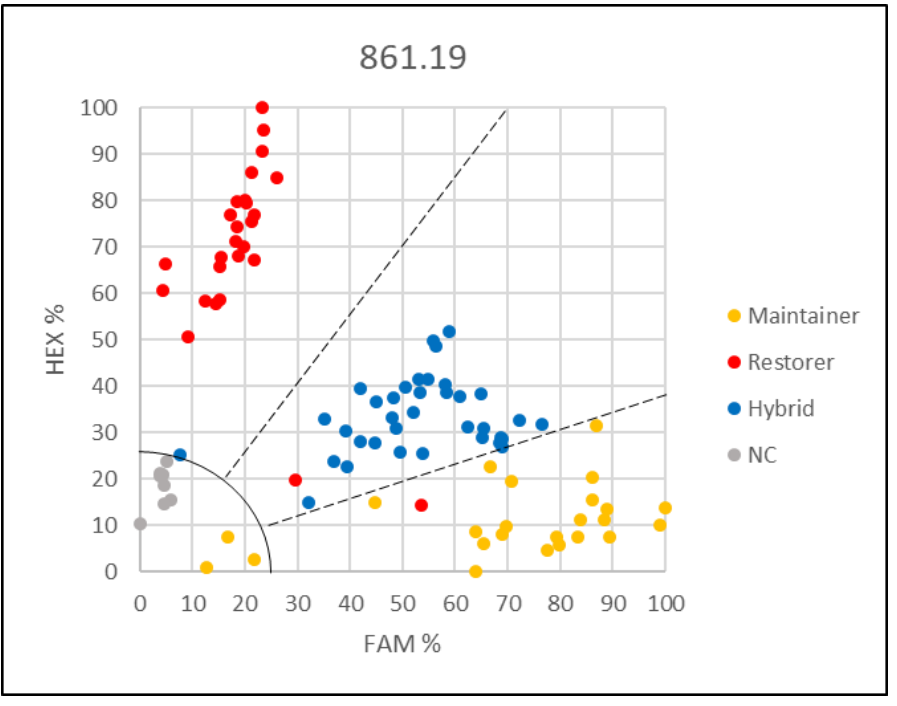

(b)

Figure 3. Grouping obtained by KASP markers (a) 841.38 and (b) 861.19. NC negative control.

Specific SNP detection by the developed KASP markers was validated by comparison to the SNP analyses performed for 10 of the maintainer lines and 10 of the restorer lines by amplicon targeted sequencing (Table 2). The nucleotides were confirmed correct in all cases, but samples of CM63 fell into the 25\% no amplification zone for KASP 841.38 and 861.19. For KASP marker 841.38, UGA-SAM1-109 indicated a heterozygous state.

Table 2. Validation of the KASP marker results by comparison with the SNP analyses from amplicon targeted sequencing.

\begin{tabular}{|c|c|c|c|c|c|c|c|c|}
\hline \multirow{2}{*}{ Common Name } & \multicolumn{4}{|c|}{ Sequence-Based SNP Analyses } & \multicolumn{4}{|c|}{ KASP Marker $^{1}$} \\
\hline & PPR621.5 & PPR621.11 & PPR841.38 & PPR861.19 & 621.5 & 621.11 & 841.38 & 861.19 \\
\hline Armavirsky 3497 & GG & $\mathrm{CC}$ & GG & GG & GG & $\mathrm{CC}$ & GG & GG \\
\hline Arrowhead & GG & CC & GG & GG & GG & $\mathrm{CC}$ & GG & GG \\
\hline CM259 & GG & $\mathrm{CC}$ & GG & GG & GG & $\mathrm{CC}$ & GG & GG \\
\hline CM63 & GG & $\mathrm{CC}$ & GG & GG & GG & $\mathrm{CC}$ & - & - \\
\hline Krasnodaret & GG & $\mathrm{CC}$ & GG & GG & GG & $\mathrm{CC}$ & GG & GG \\
\hline No. 2 & GG & $\mathrm{CC}$ & GG & GG & GG & $\mathrm{CC}$ & GG & GG \\
\hline UGA-SAM1-082 & GG & $\mathrm{CC}$ & GG & GG & GG & $\mathrm{CC}$ & GG & GG \\
\hline UGA-SAM1-109 & GG & $\mathrm{CC}$ & GG & GG & GG & $\mathrm{CC}$ & GC & GG \\
\hline UGA-SAM1-156 & GG & $\mathrm{CC}$ & GG & GG & GG & $\mathrm{CC}$ & GG & GG \\
\hline UGA-SAM1-185 & GG & $\mathrm{CC}$ & GG & GG & GG & $\mathrm{CC}$ & GG & GG \\
\hline НА342 & - & - & - & - & GG & $\mathrm{CC}$ & GG & GG \\
\hline НА383 & - & - & - & - & GG & $\mathrm{CC}$ & GG & GG \\
\hline UGA-SAM1-010 & $\mathrm{CC}$ & AA & AA & $\mathrm{CC}$ & $\mathrm{CC}$ & AA & AA & $\mathrm{CC}$ \\
\hline UGA-SAM1-024 & $\mathrm{CC}$ & AA & AA & $\mathrm{CC}$ & $\mathrm{CC}$ & AA & AA & $\mathrm{CC}$ \\
\hline UGA-SAM1-100 & $\mathrm{CC}$ & AA & AA & $\mathrm{CC}$ & $\mathrm{CC}$ & AA & AA & $\mathrm{CC}$ \\
\hline UGA-SAM1-101 & $\mathrm{CC}$ & AA & AA & $\mathrm{CC}$ & $\mathrm{CC}$ & AA & AA & $\mathrm{CC}$ \\
\hline UGA-SAM1-121 & $\mathrm{CC}$ & AA & AA & $\mathrm{CC}$ & $\mathrm{CC}$ & AA & AA & $\mathrm{CC}$ \\
\hline UGA-SAM1-136 & $\mathrm{CC}$ & AA & AA & $\mathrm{CC}$ & $\mathrm{CC}$ & AA & AA & $\mathrm{CC}$ \\
\hline UGA-SAM1-161 & $\mathrm{CC}$ & AA & AA & $\mathrm{CC}$ & $\mathrm{CC}$ & AA & AA & $\mathrm{CC}$ \\
\hline UGA-SAM1-169 & $\mathrm{CC}$ & AA & AA & $\mathrm{CC}$ & $\mathrm{CC}$ & AA & AA & $\mathrm{CC}$ \\
\hline UGA-SAM1-191 & $\mathrm{CC}$ & AA & AA & $\mathrm{CC}$ & $\mathrm{CC}$ & AA & AA & $\mathrm{CC}$ \\
\hline UGA-SAM1-204 & $\mathrm{CC}$ & AA & AA & $\mathrm{CC}$ & $\mathrm{CC}$ & AA & AA & $\mathrm{CC}$ \\
\hline RHA325 & - & - & - & - & $\mathrm{CC}$ & AA & AA & $\mathrm{CC}$ \\
\hline RHA265 & - & - & - & - & $\mathrm{CC}$ & AA & AA & $\mathrm{CC}$ \\
\hline IH-51 & - & - & - & - & GG & $\mathrm{CC}$ & GG & GG \\
\hline NS-H-27 & - & - & - & - & $\mathrm{CC}$ & AA & AA & $\mathrm{CC}$ \\
\hline
\end{tabular}




\subsection{Applying the KASP Marker 621.5 for Genetic Purity Testing}

Genetic purity testing in sunflower hybrid production requires SNP-based markers for high-throughput automated screening of breeding material. Sensitivity of the KASP marker 621.5 , which provided the best separation results, was analyzed in mixtures representing different levels of contaminations (Tables S2 and S3). In addition, reference samples representing the pure restorer line, the pure maintainer line, and the hybrids were included in the KASP assays. Two types of plant tissue, hypocotyls and leaves, were compared for their efficiency in contamination screening. To show the universal use of the KASP marker in genetic purity testing, two different sets of mixtures per plant tissue type were created. In the KASP assays based on hypocotyl mixtures, $1 \%, 3 \%, 5 \%$, and $10 \%$ contaminations grouped together with the pure restorer line sample. However, it was notable that the pure restorer line and less contaminated samples ( $1 \%$ and $3 \%$ ) were closer to the $100 \%$ HEX axis compared to samples with $5 \%$ and $10 \%$ contamination (Figure 4 ). A clear distinction was observed only in the case of $50 \%$ contamination, compared to the group of $0-10 \%$ contamination. The maintainer line was clearly separated from all other samples.

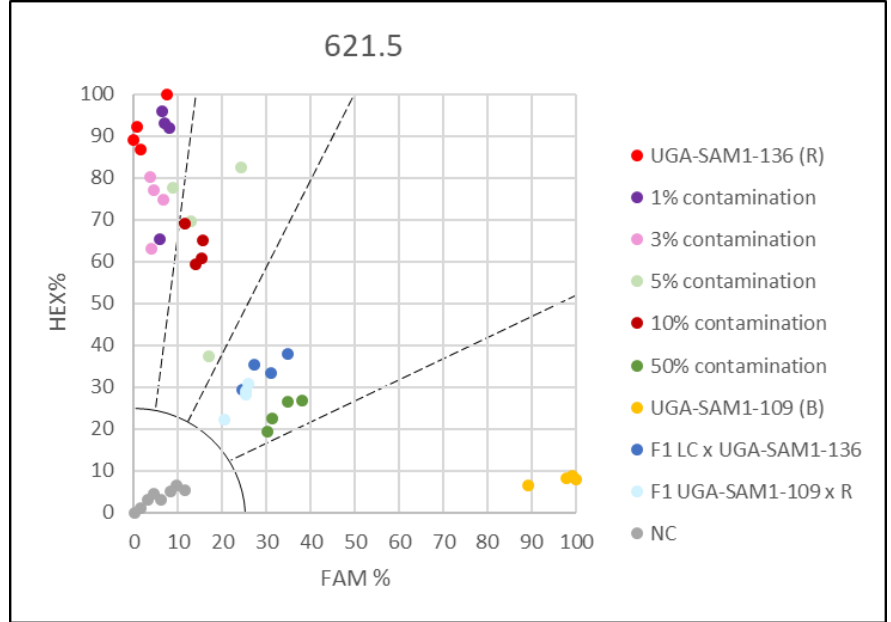

(a)

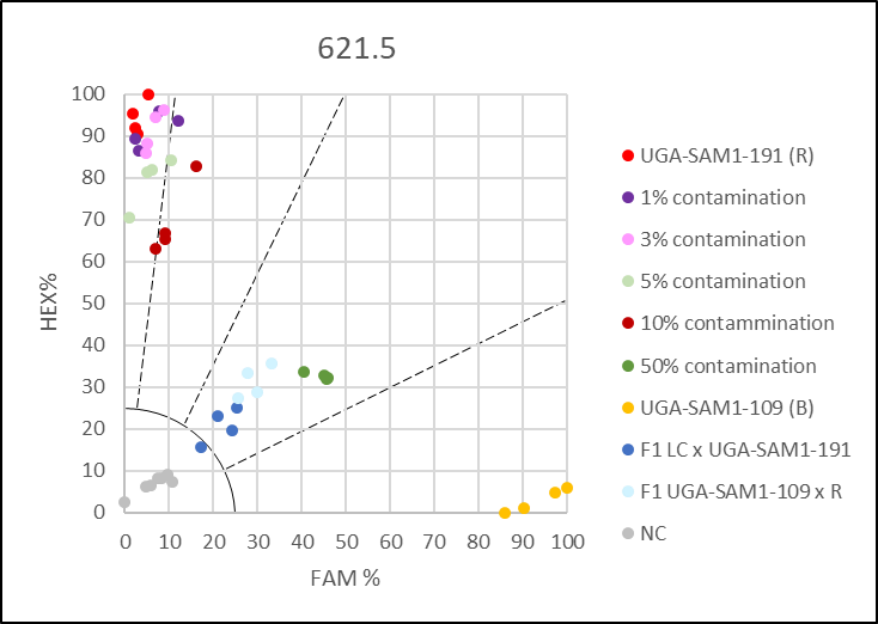

(b)

Figure 4. Genetic purity testing for hybrid breeding using hypocotyls and KASP marker 621.5. (a) Contaminations of restorer UGA-SAM1-136 with maintainer UGA-SAM1-109 were simulated and (b) Contaminations of restorer UGA-SAM1-191 with maintainer UGA-SAM1-109.

Better results were observed when leaf mixtures were used. Mixtures with $1 \%, 3 \%$, and $5 \%$ contamination grouped together with the pure restorer (Figure 5), but the mixture representing $10 \%$ contamination was clearly separated from this group as well as from the sample with 50\% contamination. In all KASP assays, the mixture representing 50\% contamination grouped together with the F1 hybrids as expected (Figures 4 and 5). Maintainer lines arranged separately from all other samples. Results obtained from different genotype sets, tested on the same tissue type, were comparable. Contaminations below $10 \%$ will require single plant analyses in order to estimate the percentage of contamination.

\subsection{Applying the KASP Markers for Single Plant Testing}

F1-hybrid seeds (cmsHA342 $\times$ RHA325) were treated with $0.8 \%$ or $1.2 \%$ EMS to obtain male sterile plants with mutations in the restorer gene Rf1. Investigating 213 sunflower plants treated with $0.8 \%$ EMS, no male-sterile plant was observed. However, using $1.2 \%$ EMS, nine out of 218 germinated plants were partially male sterile or male sterile. For verification of the plant origin, these nine male-sterile or partially male-sterile EMS-treated F1 plants, and one male fertile EMS F1 mutant with basal branching as an internal reference, were analyzed using all four KASP markers 621.5 and 621.11 (Figure 6) and 841.38 and 861.19 (Figure 7). 


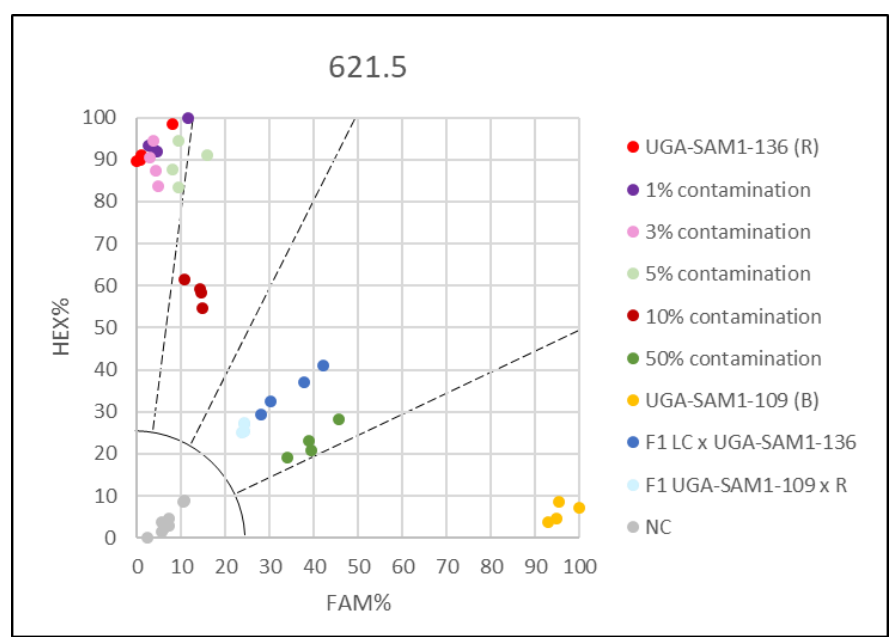

(a)

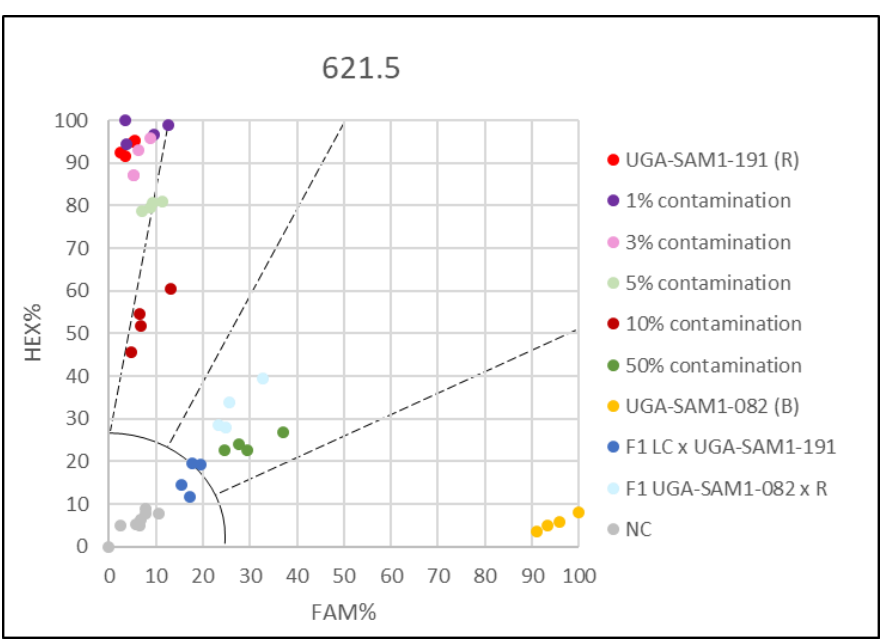

(b)

Figure 5. Genetic purity for hybrid breeding using leaves and KASP marker 621.5. (a) Contaminations of restorer UGA-SAM1-136 with maintainer UGA-SAM1-136 were simulated and (b) Contaminations of restorer UGA-SAM1-191 with maintainer UGA-SAM1-082.

For KASP markers 621.11, 841.38 and 861.19 partially male-sterile mutant Mut1 clearly grouped with the F1 hybrid cmsHA342 × RHA325 (Rf1rf1). KASP marker PPR621.5 showed no amplification for Mut1. The F1 hybrid character of the male-fertile branching mutant Mut16 was also confirmed by all four KASP markers.

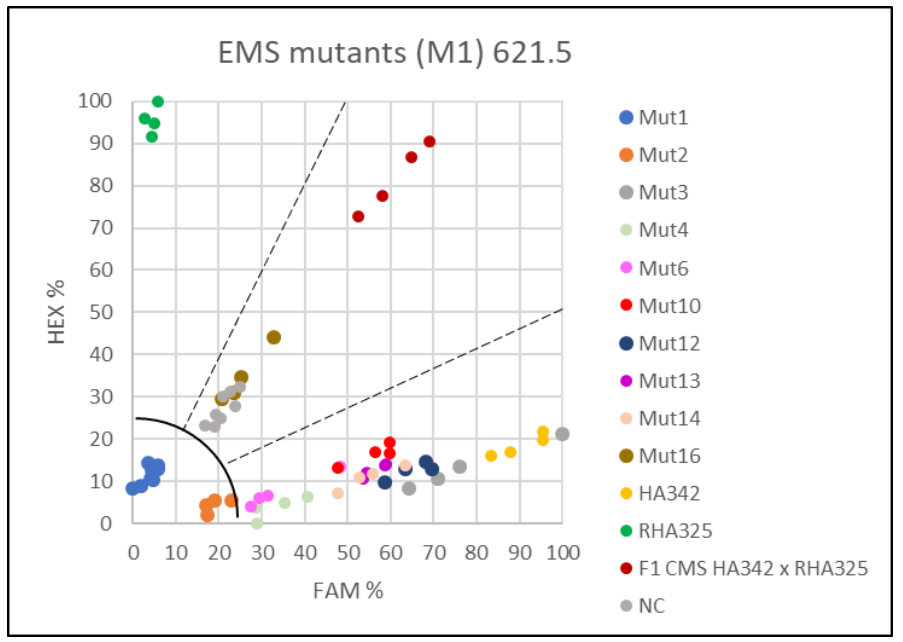

(a)

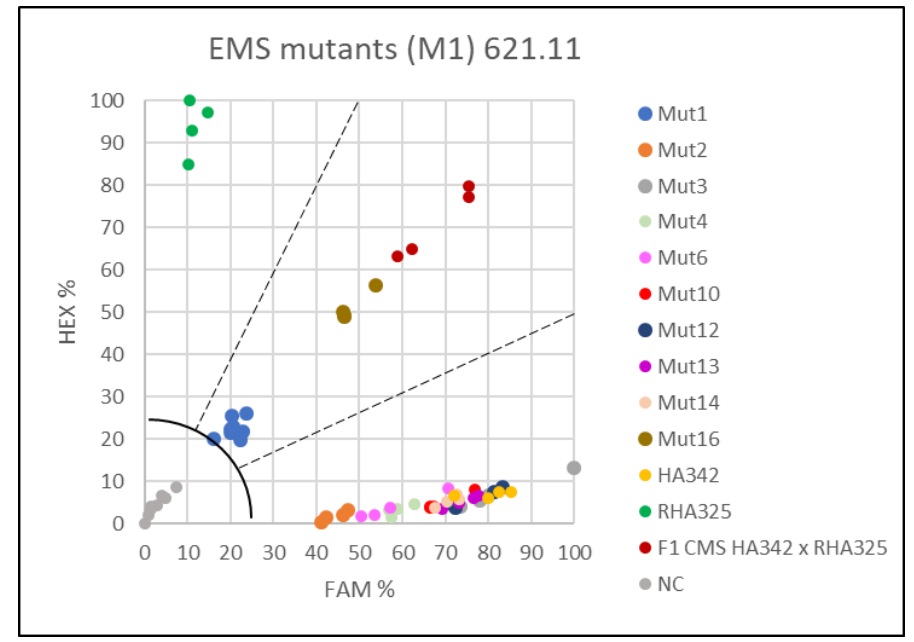

(b)

Figure 6. Investigation of the restorer locus Rf1 in EMS-treated plants (M1 generation) by application of two KASP markers. (a) Screening with KASP 621.5, (b) Screening with KASP 621.11.

Seven male-sterile EMS mutants grouped together with the maintainer line HA342 (rf1rf1) with all four KASP markers indicating that they do not contain a dominant restorer allele Rf1, neither normal nor mutated by EMS. Mutant Mut10 showed a different behavior for the two PPR621-derived KASP markers than for the other two markers. For PPR621, both KASP markers (621.5 and 621.11) grouped Mut10 with the maintainer HA342, explaining the observed partial male sterility. For the KASP markers 841.38 and 861.19, Mut 10 grouped with the F1 hybrid cmsHA342 x RHA325 detecting a recombination event at the restorer locus Rf1 between these two SNPs and the two KASP markers for PPR621. As Mut10 was partially male sterile, this recombination indicates that HanXRQr2_Chr13g0608631 (PPR621) is more important for fertility restoration of PET1 than the other two candi- 
date genes. Single plant KASP assays allowed classifying each plant into a group, either maintainer (rf1rf1), restorer (Rf1Rf1), or F1 hybrid (Rf1rf1).

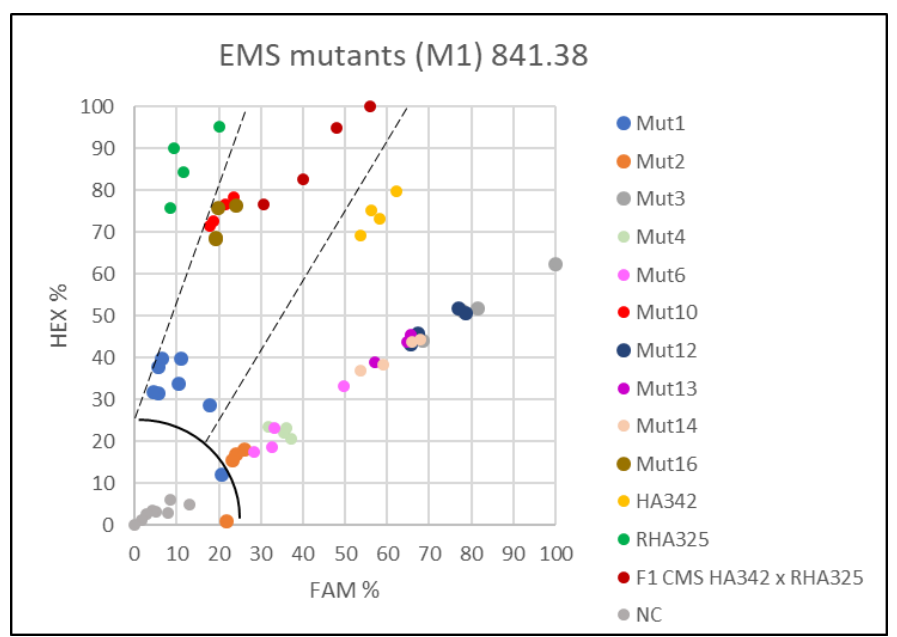

(a)

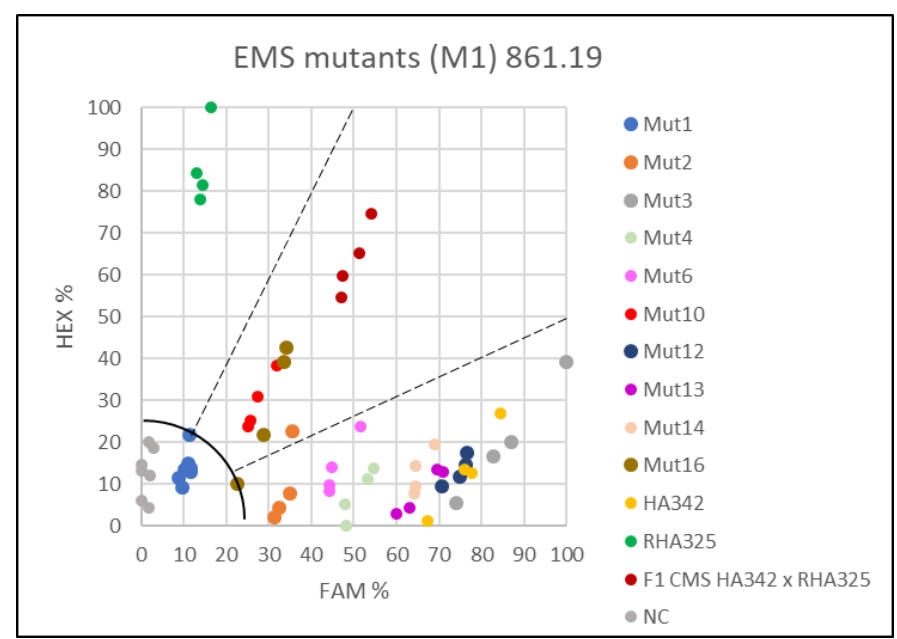

(b)

Figure 7. Investigation of the restorer locus Rf1 in EMS-treated plants (M1 generation) by application of two KASP markers. (a) Screening with KASP 841.38 and (b) Screening with KASP 861.19.

The KASP assays showed that only the partially male-sterile Mut1 and the male-fertile EMS-branching mutant Mut16 proved to be F1 hybrids, whereas Mut10 represents a malesterile recombinant plant, where a recombination event had occurred in the region between HanXRQr2_Chr13g0608631 (PPR621) and the two other genes HanXRQr2_Chr13g0609921 (PPR841) and HanXRQr2_Chr13g0609901 (PPR861) (Figure 8).

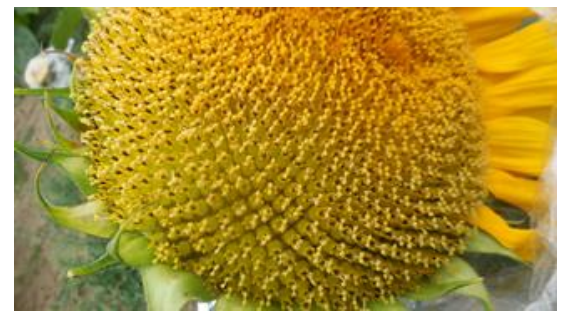

(a)

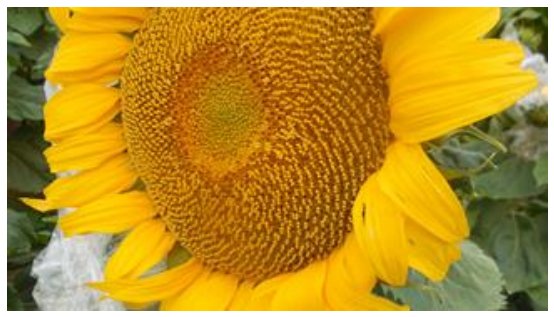

(b)

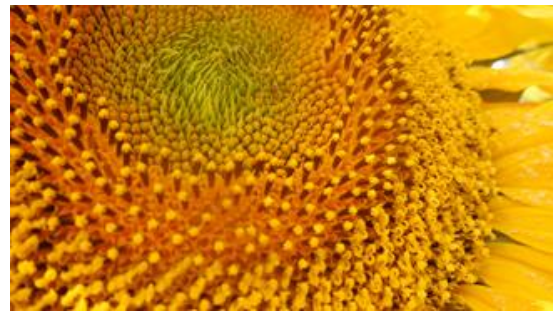

(c)

Figure 8. Phenotypic evaluation of the partially male sterile EMS-treated F1 plants Mut 1 (a) und Mut 10 (b) in comparison to the male fertile, untreated F1 hybrid cmsHA342 $\times$ RHA325 (c).

\section{Discussion}

In this study, KASP markers were exploited for the detection of Rf1-associated SNPs and tested for their efficiency in genetic purity assessment. KASP assays offer the possibility of automatization, high-throughput application, and good cost-effectiveness. All of these properties are important in both MAS and genetic purity testing as both processes involve the analysis of thousands of plants.

All four developed KASP markers (621.5, 621.11, 841.38 and 861.19) enabled discrimination between restorer lines, maintainer lines, and hybrids. KASP markers developed for the detection of two SNPs within the gene HanXRQr2_Chr13g0608631 (PPR621) had higher discrimination power compared to the KASP markers developed for the detection of the two SNPs identified in the genes HanXRQr2_Chr13g0609921 (PPR841) and HanXRQr2_Chr13g0609901 (PPR861), respectively. Even though there is a large number of reports of successful conversions of SNPs to KASP assays, not all SNPs can be successfully used to design KASP markers, because additional SNPs in the primer regions or within the 
amplified regions may interfere with design and results [27,32,33]. The sequence of the $R f 1$ gene may be complex and its structure may vary [15], thus it can be expected that not all KASP assays developed will be equally efficient in discrimination between restorer and maintainer lines. The developed KASP markers were tested across a panel of sunflower genotypes composed of restorer and maintainer lines, and hybrids. The nature of all tested genotypes was confirmed by all four KASP assays, with the exception of restorer line IH-51, which grouped with the maintainer line. This line is a restorer line for both PET1 and PET2 cytoplasm [31], and obviously does not possess the $R f 1$ gene, but the $R f-P E T 2$ gene that is positioned close to Rf1, mapping on the lower part of LG 13 [34]. Consequently, fertility restoration of PET1 in IH-51 must occur via a different restorer gene. KASP markers developed in this study were efficient enough to enable differentiation between restorer lines with different but closely mapped $R f$ genes, thus proving their discriminative power.

KASP marker 621.5 enabled the most efficient discrimination between the tested genotypes and was therefore chosen for further validation in the genetic purity testing for hybrid production. As the sensitivity of a genetic purity test is determined by the separation strength between pure and contaminated samples [35], two line sets with different contamination levels were tested. Moreover, two different tissue types were used, leaves and hypocotyl, as the efficiency of tissue disruption will have an influence on the results. Leaf tissue enabled better discrimination between the samples. The reason could lie in better tissue disruption of plant leaves compared to hypocotyls, as frozen hypocotyls were harder to be mechanically pulverized. When using leaf tissue as a DNA source, samples with $10 \%$ contamination were clearly separated from samples with lower percentages of contamination, which was not the case when hypocotyls were used. In addition, using leaf tissue has the advantage that the whole plant does not need to be destroyed for testing.

In some cases, individual plants need to be analyzed in order to increase precision in detecting contaminations. This is particularly important in seed production, where minimum varietal purity of sunflower hybrids of $95 \%$ is required, while $99.5 \%$ and $99.8 \%$ are requested for female and male line production, respectively (OECD Seed Scheme, 2021 [36]). So far, only gel-based molecular markers have been used for genetic purity screening in sunflowers $[17,19-21]$, but they are not as prone to automatization as KASP markers. Furthermore, KASP assays have proven to be very cost effective compared to other technologies used for the detection of SNPs, as in one study this technique was calculated to be 2.6 times cheaper than TaqMan assays [37]. Yuan et al. [38] even estimated that the cost per data point is only 1/50 using KASP assays compared to SNP genotyping by TaqMan. As equipment, only an RT-PCR cycler is necessary for KASPs. Taking advantage of the high-throughput possibilities of KASP assays, the detection of contamination by analysis of individual plants has been successfully performed in other plant species such as rice [26] and maize [39,40].

In our work, single plant testing was performed on phenotyped male-sterile or partially male-sterile plants obtained by EMS treatment of F1 hybrids (cmsHA342 $\times$ RHA325). For the EMS treatment, different seed charges had been combined to obtain enough seeds. All four markers clearly grouped the analyzed plants in one of the three categories (Rf1Rf1, $R f 1 r f 1, r f 1 r f 1)$. As the four KASP markers developed in this study cover the entire $R f 1$ restorer locus, it was also possible to detect a recombination event that occurred in one F1 plant. Mut 10 showed the genetic constitution of the maintainer (rf1rf1) for KASP marker 621.5 and 621.11, but for KASP 841.38 and 861.19 , it was heterozygous (Rf1rf1). This detected recombination event might be responsible for the male-sterile phenotype in Mut 10. This must be further verified by additional molecular studies. Furthermore, the KASP marker analysis clearly demonstrated that seven of the potential EMS mutants were indeed contaminants (1.6\%) and did not represent F1-hybrid mutants. The easiest explanation for these male-sterile plants is that one smaller seed charge did not represent F1 hybrids, but accidentally F2 seeds obtained by selfing of F1 hybrids. An F2 population would segregate into fertile and male-sterile plants in a ratio of 3:1. This is also supported by the fact that 
some of the male-sterile lines were branched. Branching is a recessive trait coming from the restorer line RHA325 used in the cross combination.

Single plant testing demonstrated the efficiency of the four KAPS markers in identification of possible contaminations and recombination events. It also showed that the molecular characterization of the M1 generations plants is essential in an EMS mutagenesis trial.

\section{Conclusions}

All four KASP markers $(621.5,621.11,841.38$ and 861.19$)$ identify the restorer gene haplotype of Rf1 and can be used to select for this restorer locus. KASP 621.5 proved to be the most reliable marker with the best discrimination between maintainer lines, restorer lines, and hybrids. Using KASP marker 621.5 for genetic purity testing showed that contaminations of $10 \%$ can be detected in mixtures containing leaves. For a lower percentage of contaminations, single plant assays have to be performed. The four KASP markers prove to be a universal tool to detect recombination events at the restorer locus $R f 1$.

Supplementary Materials: The following supporting information can be downloaded at: https: / /www.mdpi.com/article/10.3390/genes13030465/s1, Table S1: Lines (restorer and maintainer) and F1 hybrids with commercial tester lines; Table S2: Simulation of contaminations of restorer lines with different degrees of maintainer lines using hypocotyl pieces $(1 \mathrm{~cm})$ of 3-weeks-old sunflower seedlings; Table S3: Simulation of contaminations of restorer lines with different degrees of maintainer lines using leave pieces $(\varnothing 1 \mathrm{~cm})$ of 3-weeks-old sunflower seedlings; Table S4: Transfer of the Gene IDs in the sunflower genome assembly HanXRQv1 to the new assembly HanXRQv2 for comparison of the localization of the SNPs in the potential restorer gene candidates; Table S5: Sequences around SNPs located in the three potential restorer genes.

Author Contributions: R.H. and A.R. supervised the experiments on the field and in the laboratory, designed primers and performed KASP assays, validated and visualized the data in figures; M.S. and M.J. performed KASP assays for genetic purity testing; Y.S. planned and organized the field trials in Bandow, Germany; C.J. planned and supervised the seed and F1-hybrid production in the field station in Spain; R.H. and A.R. wrote the original draft manuscript; R.H., A.R., M.S., M.J., Y.S., D.M. and C.J. participated in reviewing and editing of the manuscript; R.H. and A.R. acquired the funding from the BMEL and the DAAD, respectively. All authors have read and agreed to the published version of the manuscript.

Funding: Seed and hybrid production were funded within the project OptiArch by Bundesministerium für Ernährung und Landwirtschaft (BMEL) and Gemeinschaft zur Förderung von Pflanzeninnovation (GFPi) under the guidance of the Fachagentur für Nachwachsende Rohstoffe (Agency for Renewable Resources) (Grant no. 22025215). Personal exchange was funded by the DAAD as a German-Serbian bilateral cooperation project (No. 451-03-01732/2017-09/3 and project code 57393592). Open access publication (OAP) was supported by the OAP fund of the University of Rostock.

Institutional Review Board Statement: Not applicable.

Informed Consent Statement: Not applicable.

Data Availability Statement: Sequences used in this publication are given in Table 1 and the Supplementary Material (Table S5).

Acknowledgments: We are grateful for the support from Joachim Propp in the field trials and the student helpers. We are also thankful for the seed production of restorer and maintainer lines and the hybrid crosses performed by Strube Research in Spain. We like to acknowledge and especially thank Laura Marek, USDA, for the maintenance, propagation, and distribution of the sunflower seeds via the Germplasm Resources Information Network (GRIN; https:/ / www.ars-grin.gov/, last accessed on 3 March 2022) of the USDA National Plant Germplasm System (NPGS) and the Plant Gene Resources of Canada (GRIN-CA) (http://pgrc3.agr.gc.ca/index_e.html, last accessed on 3 March 2022) that allowed these studies.

Conflicts of Interest: The authors declare no conflict of interest. The funders had no role in the design of the study; in the collection, analyses, or interpretation of data; in the writing of the manuscript, or in the decision to publish the results. 


\section{References}

1. Vear, F. Changes in sunflower breeding over the last fifty years. OCL 2016, 23, D202. [CrossRef]

2. Köhler, R.H.; Horn, R.; Lossl, A.; Zetsche, K. Cytoplasmic male sterility in sunflower is correlated with the co-transcription of a new open reading frame with the atpA gene. Mol. Gen. Genet. 1991, 227, 369-376. [CrossRef] [PubMed]

3. Hanson, M.R.; Bentolila, S. Interactions of mitochondrial and nuclear genes that affect male gametophyte development. Plant Cell 2004, 16, S154-S169. [CrossRef] [PubMed]

4. Korell, M.; Mösges, G.; Friedt, W. Construction of a sunflower pedigree map. Helia 1992, 15, 7-16.

5. Talukder, Z.I.; Ma, G.; Hulke, B.S.; Jan, C.C.; Qi, L. Linkage mapping and genome-wide association studies of the $R f$ gene cluster in sunflower (Helianthus annuus L.) and their distribution in world sunflower collections. Front. Genet. 2019, 14, 216. [CrossRef]

6. Kinman, M.L. New developments in the USDA and state experiment station sunflower breeding programs. In Proceedings of the 4th International Sunflower Conference, Memphis, TN, USA, 23 June 1970; pp. 181-183.

7. Kusterer, B.; Horn, R.; Friedt, W. Molecular mapping of the fertility restoration locus Rf1 in sunflower and development of diagnostic markers for the restorer gene. Euphytica 2005, 143, 35-43. [CrossRef]

8. Horn, R.; Kusterer, B.; Lazarescu, E.; Prüfe, M.; Friedt, W. Molecular mapping of the Rf1 gene restoring pollen fertility in PET1-based F1-hybrids in sunflower (Helianthus annuus L.). Theor. Appl. Genet. 2003, 106, 599-606. [CrossRef] [PubMed]

9. Yue, B.; Vick, B.A.; Cai, X.; Hu, J. Genetic mapping for the Rf1 (fertility restoration) gene in sunflower (Helianthus annuus L.) by SSR and TRAP markers. Plant Breed. 2010, 129, 24-28. [CrossRef]

10. Markin, N.; Usatov, A.; Makarenko, M.; Azarin, K.; Gorbachenko, O.; Kolokolova, N.; Usatenko, T.; Markina, O.; Gavrilova, V. Study of informative DNA markers of the Rf1 gene in sunflower for breeding practice. Czech J. Plant Breed. 2017, 53, 69-75. [CrossRef]

11. Badouin, H.; Gouzy, J.; Grassa, C.J.; Murat, F.; Staton, S.E.; Cottret, L.; Lelandais-Brière, C.; Owens, G.L.; Carrère, S.; Mayjonade, B.; et al. The sunflower genome provides insights into oil metabolism, flowering and Asterid evolution. Nature 2017, 546, 148-152. [CrossRef]

12. Goryunov, D.V.; Anisimova, I.N.; Gavrilova, V.A.; Chernova, A.I.; Sotnikova, E.A.; Martynova, E.U.; Boldyrev, S.V.; Ayupova, A.F.; Gubaev, R.F.; Mazin, P.V.; et al. Association mapping of fertility restorer gene for CMS PET1 in sunflower. Agronomy 2019, 9, 49. [CrossRef]

13. Owens, G.L.; Baute, G.J.; Hubner, S.; Rieseberg, L.H. Genomic sequence and copy number evolution during hybrid crop development in sunflowers. Evol. Appl. 2019, 12, 54-65. [CrossRef] [PubMed]

14. Horn, R.; Radanovic, A.; Fuhrmann, L.; Sprycha, Y.; Hamrit, S.; Jockovic, M.; Miladinovic, D.; Jansen, C. Development and validation of markers for the fertility restorer gene Rf1 in sunflower. Int. J. Mol. Sci. 2019, 20, 1260. [CrossRef] [PubMed]

15. Polivanova, O.B.; Sivolapova, A.B.; Goryunov, D.V.; Fedorova, A.V.; Sotnikova, E.A.; Chebanova, Y.V.; Karabitsina, Y.U.; Benko, N.I.; Demurin, Y.N.; Goryunova, S.V. Structural diversity of sunflower (Helianthus annuus L.) candidate Rf1 loci based on gene-specific PCR. Res. Crops 2021, 22, 40-46. [CrossRef]

16. Seiler, G.J.; Qi, L.L.; Marek, L.F. Utilization of sunflower crop wild relatives for cultivated sunflower improvement. Crop Sci. 2017, 57, 1083-1101. [CrossRef]

17. Pallavi, H.M.; Gowda, R.; Vishwanath, K.; Shadakshari, Y.G.; Bhanuprakash, K. Identification of SSR markers for hybridity and seed genetic purity testing in sunflower (Helianthus annuus L.). Seed Sci. Technol. 2011, 34, 59-66. [CrossRef]

18. Miklič, V.; Dušanić, N.; Jocić, S. Sunflower seed production. In Seed Production; Milošević, M., Kobiljski, B., Eds.; Institute of Field and Vegetable Crops: Novi Sad, Serbia, 2011; Volume 2, pp. 196-264. (In Serbian)

19. Gongshe, L.; Jiesheng, M.; Jie, L.; Baoqi, S. Use of RAPD markers to screen hybrids of oilseed sunflower. In Proceedings of the 15th International Sunflower Conference, Toulouse, France, 12-16 June 2000; pp. M-16-M-19.

20. Anusha, S.; Dhammaprakash, W.; Yamini, K.; Kumar, C.A.; Kumar, V.D. Assessment of genetic purity of two sunflower (Helianthus annuus L.) hybrids using sequence characterized amplified region (SCAR) markers. Indian Soc. Oilseeds Res. 2020, 15, 60-61.

21. Solodenko, A.E.; Sanalatij, A.V.; Sivolap, Y.M. Sunflower genotypes identification by means of microsatellite markers. Cytol. Genet. 2003, 38, 84-90. (In Russian)

22. Antonova, T.S.; Guchetl, S.Z.; Tchelustnikova, T.A.; Ramasanova, S.A. Development of marker system for identification and certification of sunflower lines and hybrids on the basis of SSR-analysis. Helia 2006, 29, 63-72. [CrossRef]

23. Ayalew, H.; Tsang, P.W.; Chu, C.; Wang, J.; Liu, S.; Chen, C.; Ma, X.-F. Comparison of TaqMan, KASP and rhAmp SNP genotyping platforms in hexaploid wheat. PLoS ONE 2019, 14, e0217222. [CrossRef]

24. Kante, M.; Rattunde, H.F.W.; Nébié, B.; Weltzien, E.; Haussmann, B.I.; Leiser, W.L. QTL mapping and validation of fertility restoration in West African sorghum A 1 cytoplasm and identification of a potential causative mutation for Rf2. Theor. Appl. Genet. 2018, 131, 2397-2412. [CrossRef] [PubMed]

25. Wei, B.; Bosland, P.W.; Zhang, Z.; Wang, Y.; Zhang, G.; Wang, L.; Yu, J. A predicted NEDD8 conjugating enzyme gene identified as a Capsicum candidate $R f$ gene using bulk segregant RNA sequencing. Hortic. Res. 2020, 7, 210. [CrossRef] [PubMed]

26. Qi, Y.; Wang, L.; Song, J.; Ma, G.; Wang, J. Development and utilization of the functional co-dominant KASP marker for thermo-sensitive genic male sterility in rice Oryza sativa L. Genet. Resour. Crop Evol. 2022, 69, 635-643. [CrossRef]

27. Rasheed, A.; Wen, W.; Gao, F.; Zhai, S.; Jin, H.; Liu, J.; Guo, Q.; Zhang, Y.; Dreisigacker, S.; Xia, X.; et al. Development and validation of KASP assays for genes underpinning key economic traits in bread wheat. Theor. Appl. Genet. 2016, 129, 1843-1860. [CrossRef]

28. Doyle, J.J.; Doyle, J.L. Isolation of plant DNA from fresh tissue. Focus 1990, 12, $13-15$. 
29. Patterson, E.L.; Fleming, M.B.; Kessler, K.C.; Nissen, S.J.; Gaines, T.A. A KASP genotyping method to identify Northern watermilfoil, Eurasian watermilfoil, and their interspecific hybrids. Front. Plant Sci. 2017, 8, 752. [CrossRef]

30. Oliveira, M.C.; Gaines, T.A.; Patterson, E.L.; Jhala, A.J.; Irmak, S.; Amundsen, K.; Knezevic, S.Z. Interspecific and intraspecific transference of metabolism-based mesotrione resistance in dioecious weedy Amaranthus. Plant J. 2018, 96, 1051-1063. [CrossRef]

31. Horn, R.; Friedt, W. Fertility restoration of new CMS sources in sunflower (Helianthus annuus L.). Plant Breed. 1997, 116, 317-322. [CrossRef]

32. Li, H.; Bariana, H.; Singh, D.; Zhang, L.; Dillon, S.; Whan, A.; Bansal, U.; Ayliffe, M. A durum wheat adult plant stripe rust resistance QTL and its relationship with the bread wheat Yr80 locus. Theor. Appl. Genet. 2020, 133, 3049-3066. [CrossRef]

33. Grewal, S.; Hubbart-Edwards, S.; Yang, C.; Devi, U.; Baker, L.; Heath, J.; Ashling, S.; Scholefield, D.; Howells, C.; Yarde, J.; et al. Rapid identification of homozygosity and site of wild relative introgressions in wheat through chromosome-specific KASP genotyping assays. Plant Biotechnol. J. 2020, 18, 743-755. [CrossRef]

34. Sajer, O.; Schirmak, U.; Hamrit, S.; Horn, R. Mapping of the new fertility restorer gene Rf-PET2 close to Rf1 on linkage group 13 in sunflower (Helianthus annuus L.). Genes 2020, 11, 269. [CrossRef] [PubMed]

35. Brusa, A.; Patterson, E.L.; Gaines, T.A.; Dorn, K.; Westra, P.; Sparks, C.D.; Wyse, D. A needle in a seedstack: An improved method for detection of rare alleles in bulk seed testing through KASP. Pest Manag. Sci. 2021, 77, 2477-2484. [CrossRef] [PubMed]

36. OECD Seed Schemes Rules and Regulations 2021, OECD Schemes for the Varietal Certification or the Control of Seed Moving in International Trade. Available online: https://www.oecd.org/agriculture/seeds/documents/oecd-seed-schemes-rules-andregulations.pdf (accessed on 13 January 2022).

37. Chen, Z.; Tang, D.; Ni, J.; Li, P.; Wang, L.; Zhou, J.; Li, C.; Lan, H.; Li, L.; Liu, J. Development of genic KASP SNP markers from RNA-Seq data for map-based cloning and marker-assisted selection in maize. BMC Plant Biol. 2021, 21, 157. [CrossRef] [PubMed]

38. Yuan, J.; Wen, Z.; Gu, C.; Wang, D. Introduction of high throughput and cost effective SNP genotyping platforms in soybean. Plant. Genet. Genome Biotech. 2014, 2, 90-94. [CrossRef]

39. Josia, C.; Mashingaidze, K.; Amelework, A.B.; Kondwakwenda, A.; Musvosvi, C.; Sibiya, J. SNP-based assessment of genetic purity and diversity in maize hybrid breeding. PLoS ONE 2021, 16, e0249505. [CrossRef]

40. Satya Srii, V.; Nethra, N.; Umarani, K.; Lohithaswa, H.C.; Shadakshari, Y.G.; Rajendra Prasad, S. SNP genotyping of maize (Zea mays) hybrids and parental inbred lines for genetic purity testing using double digest restriction site-associated DNA sequencing. Seed Sci. Technol. 2021, 49, 193-206. [CrossRef] 